\title{
The Effects of Text Length and Picture on Reading Comprehension of Iranian EFL Students
}

\author{
Maryam Jalilehvand \\ TESL Department, Faculty of Education, University of Malaya, 50603 Kuala Lumpur, Malaysia \\ Tel: 60-12-235-4008 E-mail: maryam_jalilvand2004@yahoo.com
}

Received: October 3, 2011

Accepted: November 16, $2011 \quad$ Published: March 1, 2012

doi:10.5539/ass.v8n3p329

URL: http://dx.doi.org/10.5539/ass.v8n3p329

\begin{abstract}
This research examined the effects of text length and picture on reading comprehension. 'Dual Coding Theory' is a powerful rationale behind using pictures and texts together. According to this theory, "information is much easier to retain and retrieve when it is dual-coded because of the availability of two mental representations instead of one." The sample consisted of 79 first grade female students from three high schools in Iran. The participants were of the same level of proficiency. The researcher utilized two texts in this study. In fact, one of these two texts was a shortened version of the original text. Using a between subject design, participants were divided into four groups. Each group read a reading comprehension text under one of four conditions: 1) long text with picture, 2) long text without picture, 3) short text with picture, and 4) short text without picture. The reading comprehension texts were accompanied by 5 multiple-choice items and 10 true-false items. Although the participants performed better on the original text, the results of the analysis of variance (ANOVA) showed that length had no significant effect on reading comprehension of Iranian high school students. However, subjects performed better on texts with picture. Therefore, picture is a key variable in influencing EFL students' reading comprehension at high school levels. These findings have pedagogical implication in the EFL and ESL fields.
\end{abstract}

Keywords: Text length, Picture, Dual coding theory, Reading comprehension

\section{Introduction}

Up to date, the English language, which is mostly used in international communication, is the most important language in the world. In many countries, there are many EFL students who have never had the opportunity to converse with any native speakers even though they have access to different types of materials written in the English language. Therefore, the need for reading and extracting information from these texts seems to be vital. As Sofiyatun (2009, p. 2) proposed, "The success of learning any subject matter depends on the competence of reading comprehension". By reading books, magazines, newspapers, and bulletins, people can gain a lot of information. So, it can be assumed that the success of obtaining information depends on the reading itself. According to Sofiyatun (2009), reading seems to be very important in a modern society. Richards and Renandya (2002 cited in Mcpherson, 2003) argued that the reason for the special focus on reading in EFL situations is that the reading skill is one of the most important goals for many students and, in fact in most EFL situations, the ability to read in a foreign language is all that students ever want to acquire. Anderson (cited in Mcpherson, 2003) believed that reading is an essential skill for EFL/ESL students and the most important skill to master. Anderson also stated that with strengthened reading skills, EFL/ESL readers will make greater development in all academic areas.

As Pearson \& Camperell (1981, p. 33) in their study reported, when complexity of structure and sentence length come together, text comprehension will be reduced. So, one of the factors that can affect text comprehension is text length.

Chastain (1988, p. 234) noted that, "language teachers usually favor short reading passages. The tendency of short passage use may have its roots in a desire not to overload the students. But it probably is an outgrowth of the idea of reading as a laborious process of deciphering a complex and sometimes unfamiliar linguistic code for which the students were required to know all grammar and vocabulary. The result has shown that students focus too much attention on language than meaning, and they read much too slowly".

Picture is another factor which can influence the level of comprehensibility of a text. Shokouhi and Parvaresh (2010, p. 9) stated that, "in order to clarify the relations among text concepts and foster deep comprehension, 
graphic organizers can be given before text. The graphic organizers can be given in the form of pictures, diagrams, matrices, maps, etc". According to Nicholas (2007, p. 1), "Children's picture books are not merely important because of the literary value they provide young readers, but they are also an essential element in the developmental reading process".

'Dual Coding Theory' is a powerful rationale behind using pictures and texts together. According to Paivio (1991), the 'Dual Coding Theory', says that there are two separate but interconnected knowledge systems: a verbal system and a visual imagery system. Verbal system deals with sequential information in discrete linguistic units and abstract concepts, and visual imagery system encodes, stores, and retrieves spatial information about concrete objects and events. Paivio (1991, cited in Vaziri Kang-e-Olia, 2000, p. 7) believed that if information is dual-coded, it will be easier to retrieve and retain due to availability of two mental representations instead of one.

\subsection{Statement of the Problem}

One of the most serious problems in education, which usually does not receive the due attention neither by students nor by teachers is the problem of reading (Dreyer \& Nel, 2003), and many students experience academic failure because of their misinterpretation of the texts (Cakir, 2008). The scores on achievement tests in L2 reading comprehension classes indicate that students are not performing well (National Center for Educational Statistics, 2005, cited in Anderson, 2007). A majority of students, even those with strong reading skills, do not like to read a reading passage, recall it and answer its questions. Further, due to the nature of school textbooks, the passages students are asked to read are often of little interest to them. Sofiyatun $(2009$, p. 3) stated that, "students argue that learning reading is boring. So, teachers should be aware of this situation and they have to create a new solution of this problem".

Clark and Paivio (1991, cited in Vaziri Kang-e-Olia, 2000, p. 4) believed that supportive pictures help explain the textual material and allow learners to build bridges between the verbal (text) and nonverbal (illustrations) information. So, the mere presence of pictures alone does not improve the reading comprehension performance. With review of previous research, some researchers (Beach, 2008; Chujo \& utiyama, 2005; Mehrpour \& Riazi, 2004; Oh, 2000; Richards, et al., 1992; Strother \& Ulijn, 1987) have investigated the effect of text length and other researchers (Caputo, 2009; Carrell, 1983; Ebrahimpur, 1999; Free, 2004; Gerrard, 2008; Haring, 1987; Lee, 1986; Nicholas, 2007; Pike, 2008; Sufiyatun, 2009; Vaziri Kang-e- Olia, 2000) have studied the effect of picture on readers' comprehension. In the above studies, the simultaneous effects of these two variables have been neglected. Therefore, the present study intends to clarify this ignored issue.

Generally speaking, the research problem of this study is to find methods to improve text comprehension levels of Iranian students at the high school level. In Iran, English is the first foreign language which is taught at many levels of education. It is a compulsory subject at these levels. By learning English, the students are expected to have a language competence including listening, speaking, reading and writing. However, according to Birjandi and Noroozi (2008, p. 48), the aim of language teaching and language learning programs in secondary and tertiary levels of education is reading. So, the aim of the current study is to explore the influences of text length and picture on EFL high school students' reading comprehension in Iran.

The results of this study will be able to shed more light on the effects of picture and text length of reading comprehension. The results of this study can also be used in selecting reading materials for teaching and testing purposes. It is hoped that the findings can provide useful information which will contribute to reading comprehension teaching purposes.

Regarding the effects of text length and picture on text comprehension, one can pose three research questions: 'does text length affect EFL students' reading comprehension?'; 'does picture affect EFL students' reading comprehension?' and another relevant research question is: 'is there any two-way interaction effect between text length and picture to comprehend a text?'

\section{Review of the Related Literature}

Numerous researches have been done to investigate techniques that facilitate reading in a foreign language. Two of these techniques which facilitate reading are text length and picture.

\subsection{Text Length}

Some studies have investigated the influence of text length on EFL text comprehension. One of the first studies was carried out by Newsom and Gaite (1971). They investigated the learning and retention of prose materials. In their study, subjects read either a 2300 -word long passage or a 300-word short passage. The results indicated that participants who read the short passage significantly outperformed those who read the long passage. In another experiment, Engineer's (1977, cited in Alderson, 2000) findings showed that when text length was longer than 
1000 words, the subjects' reading abilities could change. According to Alderson (2000), the ability to identify the main idea of long texts might be thought to be qualitatively different from the ability to identify the main in shorter texts. Strother and Ulijn (1987, cited in Alderson, 2000) compared native and non-native subjects' reading comprehension scores. The comparison was carried out by reading original passages and passages which had been simplified syntactically but not lexically. The study's results did not show a significant difference between the two groups' performances and simplified syntax did not necessarily lead to more readable texts.

Mehrpour and Riazi (2004) investigated the influence of text length on text comprehension of Iranian EFL students at the university level. The participants received two texts randomly. One group received the original text and the other group received a shortened version. The two-way ANOVA test results indicated that text length had no statistically significant effect on the subjects' reading comprehension performance. Their study supported Strother and Ulijn's (1987) study as well.

Chujo and Utiyama's (2005) study offered the firmest support for Richards et al.'s (1992) idea. They examined the effect of three independent variables (the length of the text, sample and vocabulary size) to determine text coverage. The results of their study demonstrated that when the researcher used wide vocabulary, long text and more samples, the text coverage was more stable. Beach (2008) investigated the impact of media, text length and reading rate on college students' text comprehension. The findings did not indicate a statistically significant relationship between text length and text comprehension. The results supported Mehrpour and Riazi's (2004) study and contradicted other researchers such as Oblinger and Oblinger (2005) who found that students avoided longer reading assignments.

\subsection{Picture}

Although more studies have been done on verbal learning than on visual learning, there are still many evidences of the power of visual aids. According to Jenkins \& Pany (1981, p. 171), "since pictures in text activate readers' background knowledge, they have a positive effect on text comprehension". Elster (1998, p. 68) gives support by adding that pictures are a 'scaffold' which nurture attention and motivate talks and comments.

Haring and Fry (1979) had children read a short story paired with or without illustrations and then to write down everything they could remember about it. They found that the children who had read the story with the pictures performed better on recalling more details and concluded that pictures improved comprehension. Carrell (1983) explored the influences of context, familiarity and transparency on the first language comprehension. Context was operationalized as seeing a picture or not seeing a picture. She found that native (English) readers used context and transparency to improve their comprehension. For L2 readers, only the familiarity factor influenced reading comprehension. She suggested that non-native readers were not able to use background knowledge because they were linguistically bound. Lee (1986) conducted an experiment to test Carrell's (1983) findings. The subjects were native English students studying Spanish (L2). His findings indicated a significant main effect for context. Recall of the familiar topic was enhanced when the readers were provided with a title and picture page. A few years later, Roller and Matambo (1992) examined the effect of context (picture or no picture) using Zimbabwean A-level students. The results supported Lee's (1982) study. The bilingual participants do use picture to improve their reading comprehension abilities on some passages.

According to Levie and Lentz (1982, cited in Vaziri Kang-e-Olia, 2000, p. 3), children performed better on the text which was accompanied with pictures than text that was not accompanied by pictures. Mayer and Smis (1994) supported the belief that students' performance is positively influenced by presenting text and illustration simultaneously. Chun and Plass (1996) asserted that a commonplace principle of effective learning for human is visual memory. They believed that people recall words if they are accompanied with images. Foreign words which are related to actual items or imagery strategy are easier to learn than words lacking these associations. Ebrahimpur (1999) studied the influence of pictures and vocabularies on 94 Iranian EFL students' reading comprehension. The results of his experiment showed that both pictures and vocabularies had a statistically significant effect on students' scores.

Klinger (2000) maintained that since pictures are more complicated and unique than the words that label them, more time and attention is needed to determine a picture. Thus, one looks at pictures for a long time before naming them, which makes pictures more memorable than words. Brookshire et al., (2002) measured comprehension by asking children questions about the text that required them to recall certain facts about the story. They found that those who had seen the text with pictures answered more questions correctly and concluded that illustrations improved comprehension. Free (2004) studied using pictures and words together to improve reading comprehension. The findings of the study indicated that text pictures significantly influenced reading comprehension. Gerrard (2008) supported the results of Free's (2004) study. Gerrard (2008) examined 
the impact of pictures on second-grade students' reading comprehension. Eleven second-grade participants were asked to read three narrative texts. They completed several oral tasks about three texts (written-only text, combination of text and pictures, and picture-only text). Quantitative results indicated that pictures had a significant effect on subjects' comprehension scores. Pike (2008) also studied the impact of pictures on inferential comprehension of children. Participants were 73 children from grades two to six. Regarding the type of information depicted, the results showed that pictures both facilitated and intruded with inferencing ability. More studies showed that as grade increased, this effect was reduced. Pike's findings gave support to Willows (1978) who found that when pictures were present with the text, children tended to read more slowly and less accurately. In addition, she reported that pictures had larger effects for younger children and for those who were less-skilled readers. In a recent study, Captu (2009) examined the influences of using picture and text on students' reading comprehension. The findings indicated that Picture-to-Text Learning Method appeared to be an effective learning tool.

In an attempt to complete the previous studies, this study intends to add more information by investigating the influences of text length and picture on text comprehension of Iranian EFL students at the high school level.

\section{Methodology}

\subsection{Participants}

To investigate the influences of the above mentioned factors (text length and picture) on students' reading comprehension, 79 female Iranian students were selected randomly based on Morgan's Randomization Table. These subjects were selected among first-grade students of three high schools in the city of Hashtgerd in the Tehran province. These students were representative of the first-grade high school level population who had finished the secondary level. Their age ranged from 14 to 16 . They have been studying English for 4 years.

To determine the reading ability of the participants, a standardized test from 'A First Book in Comprehension Precise and Composition by L.G. Alexander' was used. The students whose scores were one standard deviation above the mean were selected and assigned as the main participants of the present study. The participants were randomly assigned, into four groups to create a $2 \times 2$ between-groups experimental research design. The between-groups variables were the context (picture vs. no picture) and text length (long vs. short).

\subsection{Material}

The researcher utilized two texts in this study. One text was original and the other one was a shortened version of the original text. The original narrative text was taken from Okumura Nobuhiko's (1998) article. By reducing the original text to two third, the researcher gained a shortened text. The procedure for shortening the passage was based on Courchene's (1995) and Mehrpour and Riazi's (2004) criteria. By applying the criteria, the text was reduced from 309 to 218 words long text. Consequently, by following the above procedure and using pictures, each group read a reading comprehension text under one of four conditions: 1) long text with picture, 2) long text without picture, 3) short text with picture, and 4) short text without picture. All subjects were then asked to answer the 5 item multiple-choice test and 10 item true or false tests following the texts. The item types used in the test was familiar to the subjects due to the fact that they had encountered them in their previous tests.

The readability of the two texts was calculated using Flesch-Kincaid's formula. The reliability of the multiple-choice items was also calculated using the Kuder-Richardson formula. Since the original text was taken from Okumura Nobuhiko's (1998) article, the validity of the text was taken for granted.

\subsection{Procedure}

The original and shortened version of the text with two contexts (picture vs. no picture) was administered to the four groups of students participating in the study. They received the texts randomly and answered the test items.

\subsection{Data Analysis}

The most efficient way to compare the means of the four groups is ANOVA. The ANOVA statistical method produces an $F$ statistic, a value used to evaluate whether the differences in the scores are statistically significant; a probability $(p)$ of less than or equal to 0.05 is considered significant and not attributable to chance.

A two-way ANOVA was also used to test for a possible interaction effect between the factors of context and text length for four groups. The two independent or treatment variables in this study were defined as text length (long/short) and context (picture/no picture). The dependent variable was reading comprehension scores. 


\section{Results and Discussion}

Arriving at a better understanding of the effectiveness of text length and picture in comprehension of the texts, the researcher calculated the means and standard deviation of each independent variable. As a further check, the data was analyzed using the analysis of variance (ANOVA) to see whether a statistically significant difference existed between the means obtained for each independent variable.

In terms of the three research questions, the results are discussed in the following:

\section{1). Does text length affect Iranian EFL students' reading comprehension?}

Based on Tables 2 and 3, the comparison of long and short texts' mean scores indicated that the shortened version of the text was more difficult for participants to answer. Though this difference was not significant, the participants performed better on the long text. This result is in accordance to the findings of a series of studies (Strother \& Ulijn, 1987; Mehrpour \& Riazi, 2004) about the effect of text length on reading comprehension in which their results showed that text length had no significant effect on subjects' reading comprehension. Moreover, the results of the current study are consistent with Beach (2008) in which no significant effect was found for text length.

The results of the current study contradict previous studies (Oblinger \& Oblinger, 2005; Chujo \& Utliyama, 2005) in which text length had a significant effect on text comprehension. Since the subjects of this study were students of high proficiency in reading ability, the difference in results may be due to the high reading proficiency of subjects. These different results may also be due to subjects' level or may be due to the selection of the narrative texts in this study. Moreover, the researcher mixed the text length variable with the context in this study. Perhaps each variable would have different results if they were investigated individually.

2). Does picture affect EFL students' reading comprehension?

Based on Tables 2 and 3, the results showed that context had a significant effect on students' reading comprehension performance. Table 2 indicates that the mean score of students' response to reading texts with picture is higher than those reading texts without picture. This result confirmed previous studies (Brookshire et al., 2002; Captu, 2009; Free, 2004; Gerrard, 2008; Lee, 1986; Mayer \& Smis, 1994; Roller \& Matamb, 1992) in which they found a statistically significant effect for picture. The findings of the current study did not support Carrell (1983), Pike (2008), and Willows (1978). According to Carrell (1983) and Willows (1978), pictures did not have any effect on readers' reading comprehension. Pike (2008) also believed that pictures both facilitate and intrude the subjects reading comprehension. However, in this study, pictures had a significant effect on first-grade high school students. Perhaps the difference in results between this study and Carrell's (1983) is due to the subjects' level. Carrell's subjects were university students whereas the subjects of this study are first-grade high school students and according to Willows (1978), "pictures have larger influences for younger students".

$3)$. Is there a two-way interaction effect between text length and picture to comprehend a text?

The two-way ANOVA test did not indicate any significant interaction effect between text length and context on L2 reading performance. In general, the study suggests that the overall performance of the students who read long/picture text were slightly better than students who read the long/no picture text. On the other hand, the students reading the short/picture text performed slightly better than the students reading short/no picture text. It can be concluded that text length and context do not have any interaction effect in this study. In other words, the effect of text length on students is the same regardless of picture and the effect of picture is the same regardless of the text length. This result is in direct agreement with Willows (1978) who found that when pictures were presented with the text, children tended to read more slowly and less accurately. In addition, she reported that pictures had larger effects for younger learners and for those who were less-skilled readers. According to Pike (2008), pictures both aided and impeded reading comprehension. It depends on the type of information depicted, but as grade increased this effect is reduced.

\section{Conclusion}

The current research was conducted to explore the influences of text length and picture on text comprehension of EFL students. Regarding the first research question, that is, whether the students performed differently when they read texts with similar contents but in different lengths, the findings revealed that the length of the text does not influence the reading comprehension of readers. In light of the second research question, of whether context affects EFL students' performance, the findings showed that picture had a significant influence on learners' performance. The subjects who read texts with picture outperformed the students who read texts without picture. For the third research question, no significant interaction effect was observed between text length and picture. Based on these results, the EFL reading teachers do not have to restrict themselves to using short texts when they 
teach and test reading comprehension, but picture can be applied as a scaffold to help students comprehend the text efficiently. The results of this study can not be generalized to all students since the students who participated in this study are not representative of all students. The design of the current study was between-subjects design. The results may be different with within-subjects design. Thus, further research should consider using less-skilled students and older students. Further research should also be done on other text types and different levels of students. Such studies will have clear pedagogical implications for the teaching of EFL/ESL reading comprehension.

\section{References}

Alderson, J. C. (2000). Assessing reading. Cambridge: Cambridge University Press. http://dx.doi.org/10.1017/CBO9780511732935

Anderson, S. A. (2007). The effect of music on the reading comprehension of junior high school students. ProQuest Information and Learning Company.

Beach, K. L. (2008). The effect of media, text length, and reading rates on college student reading comprehension levels. Ph.D thesis. ProQuest LLC, University of Phoenix.

Birjandi, P. \& Noroozi, I. (2008). The effect of cognitive strategies training on reading comprehension of male and female Iranian students. Foreign Language Teaching Journal, 22(87), 41-48.

Brookshire, J., Scharff, L.F. \& Moses, L.E. (2002). The influence of illustrations on children's book preferences and comprehension. Reading Psychology, 23, 323-339. http://dx.doi.org/10.1080/713775287

Cakir, O. (2008). The effect of textual differences on children's processing strategies. Reading Improvement. ProQuest educational journals, 45(2), 69. [Online] Available: http://findarticles.com/p/articles/mi_hb6516/is_2_45/ai_n29452065/(summer 2008)

Caputo, J. M. (2009). Effects of using a picture-and-text decoding method on student comprehension in a high school fundamental biology course with an agriculture emphasis. MA thesis. ProQuest LLC, University of California.

Carrell, P. L. (1983). Three components of background knowledge in reading comprehension. Language Learning, 33(2), 183-207. http://dx.doi.org/10.1111/j.1467-1770.1983.tb00534.x

Chastain, K. (1988). Developing second-language skills: Theory to practice (3rd ed.). San Daigo, CA: Harcourt, Brace, Jovanovich.

Chujo, K. \& Utiyama, M. (2005). Understanding the role of text length, sample size and vocabulary size in determining text coverage. Reading in a Foreign Language, 17(1). [Online] Available: http://nflrc.hawaii.edu/rfl/April2005/ (September 2005)

Chun, D. M. \& Plass, J. L. (1996). Effects of multimedia annotations on vocabulary acquisition. The Modern Language Journal, 80(2), 183-198. http://dx.doi.org/10.1111/j.1540-4781.1996.tb01159.x

Courchene, R. (1995). An alternative method for teaching and testing reading comprehension. TESL Canada Journal, 12, 50-8.

Dreyer, C. \& Nel, C. (2003). Teaching reading strategies and reading comprehension within a $\begin{array}{lllll}\text { technology-enhanced } \quad \text { learning } & \text { environment. } & \text { System, } & 31, & 349-365 .\end{array}$ http://dx.doi.org/10.1016/S0346-251X(03)00047-2

Ebrahimpur, A. (1999). The effects of two types of pre-reading activities on EFL reading pre-university students. MA thesis. Shiraz University, Iran.

Elster, C. A. (1998). Influences of text and pictures on shared and emergent readings. Research in the teaching of English, 32(1), 43-78.

Free, W. P. (2004). Pictures and words together: Using illustration analysis and reader- generated drawing to improve reading comprehension. Ph.D theses. ProQuest Information and Learning Company.

Gerrard, E. E. (2008). Picturebooks as visual literacy: The influence of illustrations on second-graders' comprehension of narrative text. MA these. ProQuest LLC. University of Maryland.

Haring, M. J. (1987). The effect of pictures on reading comprehension. Ph.D thesis. Arizona State University.

Haring, M.J. \& Fry, M.A. (1979). Effect of pictures on children's comprehension of written text. Educational Communication and Technology Journal, 27, 185-190. 
Jenkins, J. R. \& Pany, D. (1981). Instructional variables in reading comprehension. In J. T. Guthrie (Ed.), Comprehension and teaching: Research reviews. Newark, Delaware: International Reading Association, 163-202.

Klinger, W. (2000). Effects of pictures on memory and learning. [Online] Available: http://www.scribd.com/doc/11437171/effects- of- pictures- on- memory-learning

Lee, J. F. (1986). Background knowledge and L2 reading. The Modern Language Journal, 70 (4), 350-354. [Online] Available: http://www.jstor.org/stable/326812 (May 2009)

Mayer, R. E. \& Sims, V. K. (1994). For whom is a picture worth a thousand words? Extensions of a Dual-Coding Theory of Multimedia Learning. Journal of Educational Psychology, 86(3), 389-401. http://dx.doi.org/10.1037/0022-0663.86.3.389

Mcpherson, P. (2003). Reviewed work: Anderson, N. (1999). Exploring second language reading: Issues and strategies. Heinle \& Heinle. Reading in a Foreign Language, 15(1),76-78.

Mehrpour, S. \& Riazi, A. (2004). The impact of text length on EFL students' reading comprehension. Asian EFL Journal.

Newsom, R. S. \& Gaite, A. J. H. (1971). Prose learning: Effects of pretesting and reduction of passage length. Psychological reports, 28, 123-129. http://dx.doi.org/10.2466/pr0.1971.28.1.123

Nicholas, J. L. (2007). An explanation of the impact of picture book illustrations on the comprehension skills and vocabulary development of emergent readers. Ph.D thesis. Louisiana State University.

Oblinger, D. \& Oblinger, J. (2005). Is it age or IT: First steps toward understanding the Net generation. Retrieved from University of Phoenix EBSCOhost database (19 June 2006).

Oh, S. Y. (2000). Two type of input modifications and EFL reading comprehension: Simplification versus elaboration. TESOL Quarterly, 34(4).

Okumura, N. (1998). The variances in L2 reading ability in accordance with text type: Expository and narrative materials. SURCLE, 1, 16-25.

Paivio, A. (1991). Dual-coding theory: Retrospect and current status. Canadian Journal of Psychology, 45, 255-287. http://dx.doi.org/10.1037/h0084295

Pearson, P. D. \& Camperell, K. (1981). Comprehension of text structures. In J. T.Guthrie (Ed.), Comprehension and teaching: Research Reviews. Newark, Delaware: International Reading Association, 27-55.

Pike, M. M. (2008). The role of illustrations in children's inferential comprehension. MA thesis. University of Guelph.

Richards, J. C., Platt, J. \& Platt, H. (1992). Longman dictionary of language teaching and applied linguistics. London: Longman.

Roller, C. M. \& Matambo, A. R. (1992). Bilingual readers' use of background knowledge in learning from the text. TESOL Quarterly, 26(1), 129-141. [Online] Available: http://www.jstor.org/stable/3587372 (March 13, 2009)

Shokouhi, H. \& Parvaresh, N. (2010). Post-adjunct reading comprehension questions and meaning construction: A case of gender study. Journal of Language Teaching and research, 1(1), 8-19.

Sofiyatun, E. (2009). The use of picture stories to improve reading comprehension (A classroom action research at the fifth year students of SD N I Pledokan, Sumowono, Semarang in 2008/2009 academic year). Bachelor degree. Muhammadiyah university of Surakarta.

Vaziri Kang-e-Olia, S. M. (2000). The effect of textual and pictorial Glosses on reading comprehension ability of Iranian high school students. MA thesis. Teacher Language University, Iran.

Willows, D.M. (1978). A picture is not always worth a thousand words: Pictures as distractors in reading. Journal of Educational Psychology, 70, 255-262. http://dx.doi.org/10.1037/0022-0663.70.2.255 
Table 1. 2 × 2 Factorial Design Matrixes

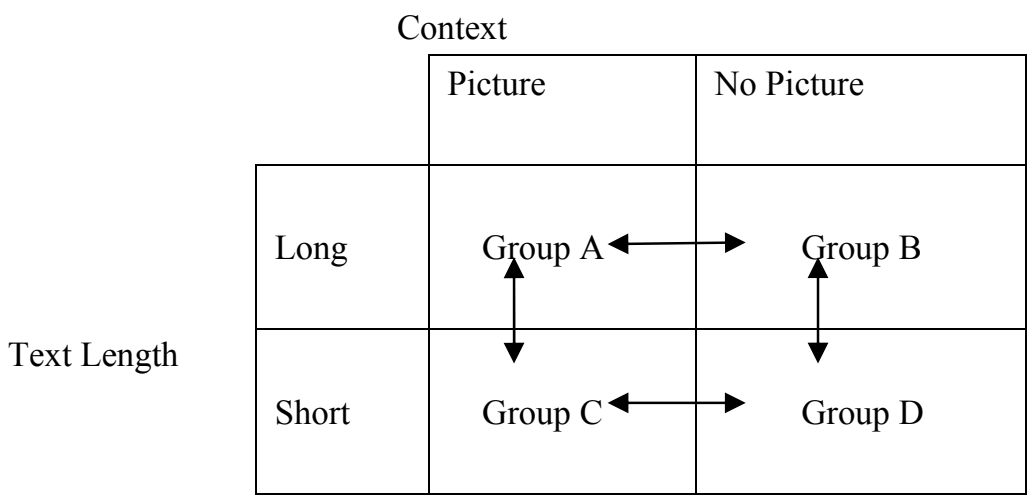

The results from Group A were compared to the results of Group B to determine if context (picture/no picture) affected reading comprehension. The results of Group $\mathrm{C}$ were compared to the results of Group D to determine if context (picture/no picture) affected reading comprehension. In addition, the results from Group A were compared to Group $\mathrm{C}$ to determine if the length of the text (long/short) affected reading comprehension. In addition, the results of Group B were compared to Group D to determine if the length of the text (long/short) affected reading comprehension (Table 1).

Table 2. Descriptive Statistics for Text Length and Context

\begin{tabular}{|c|c|c|c|c|}
\hline Length & context & Mean & Std. Deviation & $\mathrm{N}$ \\
\hline \multirow[t]{3}{*}{ Long } & picture & 86.31 & 12.664 & 19 \\
\hline & no picture & 77.77 & 15.252 & 21 \\
\hline & Total & 81.83 & 14.559 & 40 \\
\hline \multirow[t]{3}{*}{ Short } & picture & 85.26 & 12.877 & 19 \\
\hline & no picture & 74.66 & 18.174 & 20 \\
\hline & Total & 79.82 & 16.507 & 39 \\
\hline \multirow[t]{3}{*}{ Total } & picture & 85.78 & 12.608 & 38 \\
\hline & no picture & 76.25 & 16.604 & 41 \\
\hline & Total & 80.84 & 15.484 & 79 \\
\hline
\end{tabular}

Table 3. Results of Two-Way ANOVA Test for Text Length and Context

\begin{tabular}{lrrrrr}
\hline Source & SS & df & MS & $F$ & Sig. \\
\hline Length & 85.37427 & 1 & 85.37427 & 0.381127 & 0.539 \\
Context & 1804.823 & 1 & 1804.823 & 8.057062 & 0.006 \\
Length * context & 20.88983 & 1 & 20.88983 & 0.093256 & 0.761 \\
Error & 16800.38 & 75 & 224.0051 & & \\
\hline Total & 534993.8 & 79 & & & \\
Corrected Total & 18701.03 & 78 & & &
\end{tabular}

a. $\mathrm{R}$ Squared $=.102($ Adjusted R Squared $=.066)$ 
Table 2 shows the descriptive statistics and Table 3 indicates the results of ANOVA test for text length and context. As indicated in Table 2, the mean scores of the long (original) and short version of the text are not so different from each other $\mathrm{M}=81.83$ and $\mathrm{M}=79.82$. The ANOVA results in Table 3 also shows that $F$ value is not statistically significant $F=0.381, p>0.05$ for text length variable. So, it can be interpreted that the performance of students reading long text is not different from the students reading short text.

Furthermore, as Table 2 presents, mean scores for texts with picture and without picture are $\mathrm{M}=85.78$ and $\mathrm{M}=$ 76.25. The comparison of the two mean scores indicates that the performance of students reading text with picture is different from students reading text without picture. The analysis of data in the ANOVA test revealed that $F$ value is statistically significant $F=8.057, p<0.05$ for context variable. So, there is a statistically significant difference for the two groups' performance.

Using text length and context as independent variables and reading comprehension scores as the dependent variable, the two-way analysis of variance (ANOVA) was then conducted to determine whether there is a significant effect between text length and context. For conducting the two-way ANOVA, text length and picture were treated as independent variables and reading comprehension scores as the dependent variable. As can be seen in Table 3 , the $F$ value is not statistically significant $F=0.093, p>0.05$. So the interaction effect was not found to be significant for text length and context.

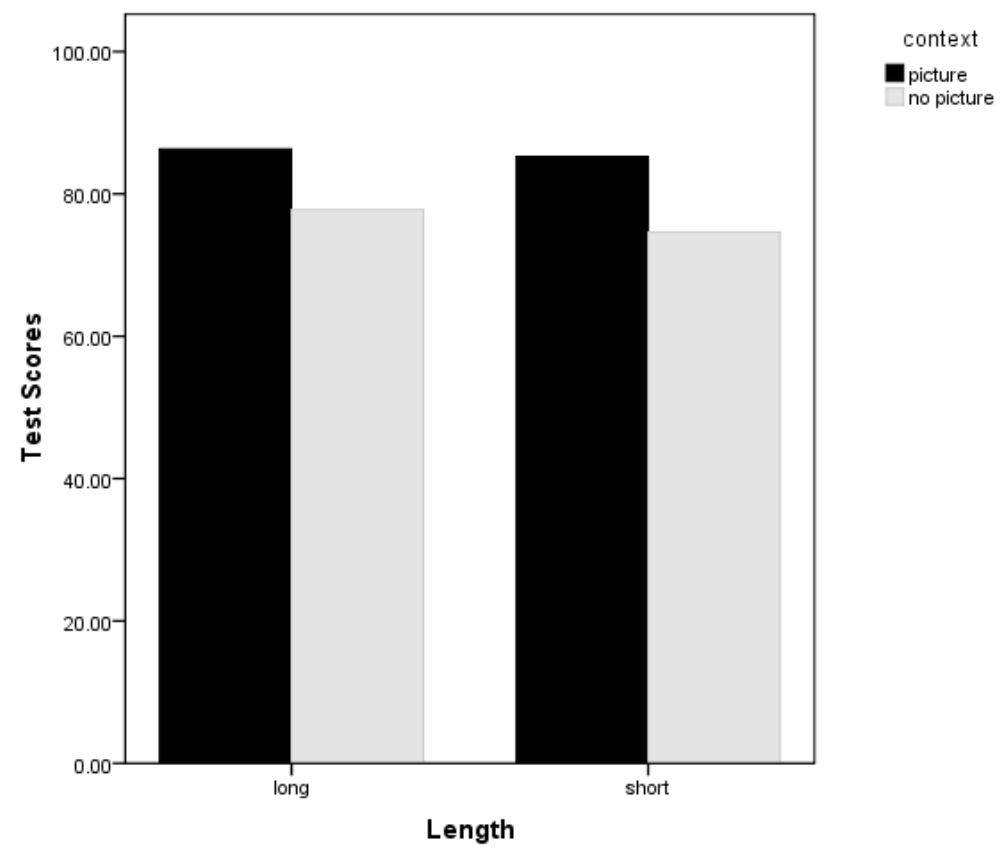

Figure 1. Mean comparisons of interaction effect for text length and context

The descriptive statistics for both independent variables (text length \& context) were also compared in Figure 1. As displayed in Table 2, the mean scores of long and short texts with pictures are $\mathrm{M}=86$ and $\mathrm{M}=85$. The difference of these two mean scores is about 1 point. The difference between long and short texts without picture is $\mathrm{M}=78$ and $\mathrm{M}=75$. The difference is 3 points. The difference of 3 is not so different from 1 . This difference shows that the effect of text length on reading comprehension does not depend on the different levels of context. So, Figure 1 clearly reveals that there is no interaction effect between text length and context. 